\title{
Violearn: Um Protótipo Para Ensino de Teoria e Prática Musical por Violão
}

\author{
Gustavo Milcharek Dávila $^{1}$, Josiane Brietzke Porto ${ }^{1}$ \\ ${ }^{1}$ Escola Politécnica - Universidade do Vale dos Sinos (UNISINOS) \\ Av. Unisinos, 950 - 93.022-750 - São Leopoldo - RS - Brasil \\ gmilcharek@gmail.com, josibrietzke@unisinos.br
}

\begin{abstract}
Technological advances have facilitated access to knowledge and solutions for mobile devices, but there are few quality options for teaching music by guitar. This research created an application prototype in this area, under Design Science Research, with gamification, teaching material and study guide, to support remote learning and the development of desired skills in guitar playing. The evaluation by experts and users showed smartphones as allies in music education and the incorporation of gamification, as efficient in the engagement and commitment of users with their studies. The sequential program content and in evolutionary and gradual modules proved to be effective in teaching music and guitar.
\end{abstract}

Resumo. Avanços tecnológicos facilitaram acesso ao conhecimento e soluções para dispositivos móveis, mas são poucas opções de qualidade para ensino de música por violão. Esta pesquisa criou um protótipo de aplicativo nessa área, sob Design Science Research, com gamificação, material didático e guia de estudos, para apoiar aprendizado remoto e o desenvolvimento de habilidades desejadas na execução por violão. A avaliação por especialistas e usuários mostrou smartphones como aliados no ensino da música e a incorporação de gamificação, como eficiente no engajamento e comprometimento dos usuários com seus estudos. O conteúdo programático sequencial e em módulos evolutivos e graduais mostrou-se efetivo no ensino da música e do violão.

\section{Introdução}

A música é uma das formas de entretenimento mais consumidas no Brasil, sendo que $79 \%$ dos brasileiros ouvem música diariamente (ABRAMUS, 2019). Além de altamente consumida, a música tem papel importante na educação. Em estudo anterior, com dois grupos de estudantes, entre 8 a 10 anos, no qual um deles seguiu os estudos sem aulas de música e o outro recebeu aulas de música, 3 vezes por semana, durante 5 meses constatou-se aumento significativo na aprendizagem de Português e de Matemática, melhorondo as notas dos alunos desse último grupo (Cogo-Moreira et al., 2013).

No mercado da educação digital existem diversos produtos de ensino, com cursos e treinamentos de música, em geral. Dentre as plataformas, se destacam Udemy, Coursera, Skillshare e até o YouTube, com canais de cursos gratuitos de música, apesar de não ser plataforma específica de ensino. Ainda que existam tais opções, a demanda por aprendizagem online continua aumentando nos últimos anos, sendo intensificada em nível global, em 2020, devido às restrições impostas e ao isolamento social, por razão da pandemia de Covid-19 (UNA-SUS, 2020). Em 2020, a Udemy reportou aumento de 
$425 \%$ no consumo mundial de cursos e treinamentos em todos segmentos e de $55 \%$ na criação de cursos para música na sua plataforma. Contudo, nenhuma delas foi construída com o fim de ensino de música por meio de violão especificamente e, por exigir estratégia de ensino peculiar, tais opções não proporcionam uma experiência de aprendizagem ideal ao aluno, pois "todo instrumento requer certas habilidades mecânicas para a produção sonora" (Pimentel, Filippo e Santoro, 2020, p. 16).

Tendo em vista a importância da música na educação, a alta demanda atual e o fato de que as maiores soluções similares existentes no mercado não são focadas no ensino da música pelo instrumento de violão, esta pesquisa teve a seguinte questão: Como melhorar o ensino de teoria e prática musical por meio de violão, através de um aplicativo móvel? Em busca de resposta para tal questão, essa pesquisa construiu um protótipo de aplicativo móvel, voltado para ensinar música por meio de violão exclusivamente, sob o método Design Science Research (DSR). Desse modo, se busca um artefato útil e relevante para tornar o ensino de música mais acessível e didático para os interessados em aprender música, via esse instrumento. Para alcance desse objetivo geral foram difinidos objetivos específicos: (i) Definir material didático e a trilha de ensino, com apoio de um professor de música; (ii) Especificar os requisitos de funcionamento e projetar a arquitetura da solução; (iii) Desenvolver uma versão Beta do protótipo, com base nos requisitos levantados e no projeto da arquitetura; (iv) Avaliar essa versão Beta do protótipo, com especialistas e potenciais usuários.

Os resultados dessa pesquisa são relevantes e importantes tanto para interessados com vontade de aprender música e tocar violão, quanto para o ramo musical em si, pois pode contribuir para facilitar o ingresso de novos musicistas e compositores na área. Ademais podem ser referência para criação de aplicativos de ensino de outros instrumentos musicais, tendo a base teórica e os procedimentos metodológicos adotados no projeto e desenvolvimento de um artefato útil à sociedade, com rigor científico. Professores de música e, principalmente, de violão podem usá-lo como apoio ou referência para os seus planos de aula. $\mathrm{O}$ material didático apresentado no artefato pode ser usado como reforço ou, até como base, para o ensino de música e de violão, tanto em aulas com professores particulares, quanto em escolas de música.

O aplicativo evoluído a partir do protótipo da pesquisa pode apoiar o ensino de música e dar maior acessibilidade a recursos de aprendizagem musical, pois será criado para smartphones e disponibilizado publicamente. Segundo o IBGE (2020), 79,3\% de brasileiros possuem celular próprio e é o equipamento mais usado para acesso a internet, encontrado em 99,2\% dos domicílios com esse serviço. Outro possível benefício é a mobilidade, pois o usuário pode acessar as aulas de qualquer lugar, desde que esteja com o seu instrumento e o celular em mãos, além de boa conexão via Internet.

Apesar de ferramentas existentes no mercado, as principais não tem suporte ao Português. Isso impede aprendizado e acompanhamento das aulas daqueles não fluentes em outras línguas. Esse fato amplia a geração de valor e a importância dessa pesquisa, pois o aplicativo proposto pode ampliar a acessibilidade ao conhecimento de música no idioma oficial do Brasil e aos mais vulneráveis da sociedade. Inclusive, o uso de meios digitais na educação pode ser uma forma de combater diferenças sociais, bem como tratar dificuldades de pessoas, com necessidades especiais (Ceccon e Porto, 2020). Além dessa introdução, esse artigo possui mais 4 seções: a 2 trata da base teórica; a 3 de aspectos metodológicos; a 4 de resultados e discussão; a seção 5, considerações finais. 


\section{Fundamentação Teórica}

Sob DSR, além do pilar histórico da música e seu ensino, aproveitado para criação de material de futuro módulo, a ser incorporado em nova versão do protótipo, a fundamentação teórica dessa pesquisa abarcou em profundidade informática na educação musical, gamificação na educação, ensino de violão por aplicativos, análises comparativas de produtos similares existentes e trabalhos relacionados. Em razão de espaço resume-se essa seção consideravelmente, enfatizando esses últimos pilares.

Avanços tecnológicos estão transformando a relação das pessoas com a música. Para Scotti (2011), a Internet possibilita que as pessoas tenham variedade de opções musicais, permite com que se relacionem, divulgando, aprendendo e transmitindo este material musical, além de mobilidade, que traz flexibilidade para assistir aulas em qualquer lugar. Iniciativas surgiram para se apropriar do uso dos celulares no ensino e dentre as justificativas estão mobilidade, portabilidade e conectividade via Internet, ampliando formas de comunicação e de acesso à informação (Fonseca, 2013).

Por sua vez, o ensino do violão é algo popular mundo afora. Segundo Wee [2010], se deve ao fato de não ser tão difícil aprender, quando comparado com outros instrumentos (como bateria ou piano), além de ser mais barato. Outro fator para a sua popularização é o fato do instrumento ser portátil. Apesar disso, o autor destaca que seu aprendizado requer solídos conhecimentos em diversas categorias relacionadas. Em relação ao ensino do violão por aplicativos, as opções são vastas, quando se procura por "aprender violão" em lojas de aplicativos. Dentre as opções, duas se destacam por estarem relacionadas a este trabalho, foram obtidas na Play Store (em 20/11/2020) e testados na versão gratuita, sendo possível experimentar na prática a metodologia de ensino empregada e averiguar funcionalidades semelhantes e diferentes.

O Yousician apresenta conteúdo em vídeos, com níveis de experiência no instrumento. Oferece treinamento desde afinação até treinamento auditivo e aulas de como tocar músicas populares. Possui função de instrumento virtual, que mostra cordas e parte do braço em que deve ser tocado, com a música sendo tocada ao fundo, para que o aluno acompanhe corretamente, seguindo instruções exibidas na tela. Usa gamificação para engajar e manter usuários motivados a continuar seu progresso. Em maio de 2021, possuía nota 4,3 de 5,0 na Play Store, mostrando cumprir o que propõe. Porém, alguns comentários ressalvam limitações do plano gratuito, como limite de tempo nas aulas e o fato de ser em Inglês. Aparenta ter qualidade e entrega valor aos usuários, mas limitações de idioma e do plano gratuito pesam e atrapalham a rotina de aprendizagem.

A outra opção é o Coach Guitar, que possui forma peculiar de informar notas e acordes, usando cores diferentes para cada corda e dedo correto. Oferece tutoriais ensinando a tocar diversas músicas famosas. Estas aulas são todas em vídeo, mostrando instrutor tocando (tanto com mão direita quanto esquerda) e braço virtual do instrumento abaixo. Na gratuita, as aulas ensinando a tocar as músicas são limitadas a uma parte delas, que só podem ser acessadas completamente, na versão paga. Possui versão em Português e suas aulas em vídeo, geralmente, são apenas o instrutor tocando a música em diferentes velocidades, sem apresentar nenhuma fala. Permite ao usuário selecionar modo para que aulas sejam tocadas lentamente, facilitando acompanhamento do instrutor. Não foi encontrada ferramenta de afinação do instrumento nem sistemas de recompensa e gamificação. Ao navegar no aplicativo, diversas vezes foram encontrados erros nos vídeos, que impediram de assisti-los até o final. Na Play Store, em maio de 
2021, a sua nota era 3,6 de 5,0, abaixo do Yousician. Parte dos comentários são positivos, mas com queixas em relação à performance, ocorrência de erros e comportamentos inesperados em funções, além do preço alto do premium.

No que tange aos trabalhos anteriores relacionados, Wee [2010] criou o GuitarApprentice para ensino do violão, onde o usuário toca os acordes e o aplicativo grava e avalia se está sendo bem executado. O diferencial foi a busca pelo melhor algoritmo de detecção dos acordes. Segundo esse autor é difícil para iniciantes saberem o quão bem estão aprendendo e evoluindo na performance do instrumento, devido ao fato de muitos aprenderem o instrumento, via fontes online e não em escola de música ou com professores de violão, não tendo avaliação do desempenho por especialista. São apresentadas informações relevantes sobre o violão e sua aprendizagem, teorias de ensino como a de tentativa e erro, aprendizagem por insight e a experiencial. Conforme o estudo, o aplicativo cumpriu o seu propósito, conforme a percepção dos usuários e demonstração de interesse em usá-lo para treinamento musical.

Já, Santana e Rovaron (2020) avaliaram o uso de aplicativos na aprendizagem musical, por um aplicativo de ensino do violão para Android, utilizando a Transformada de Fourier para o processamento do áudio, que permite aos usuários a introdução da teoria musical básica e os primeiros passos para se tocar um violão. $\mathrm{O}$ aplicativo conta com um afinador, um metrônomo e as aulas. Na sessão de aulas são apresentadas seis aulas com diferentes temáticas, contemplando a teoria musical e o ensino do violão. As primeiras quatro aulas apresentam um quiz com conteúdo de teoria musical e o aluno precisa obter determinado aproveitamento, para seguir para as próximas aulas. As duas últimas aulas apresentam conteúdo prático para tocar violão. Os autores concluíram que o uso de aplicativos favorece a aprendizagem de teoria musical, porém, não substitui aulas presenciais, principalmente, quando se trata de pessoas leigas.

Brasileiro (2017) investigou o uso de celulares para ensino de instrumento pelo Yousician. O autor discorreu sobre o uso de tecnologia na música, avanços tecnológicos e novas tecnologias na educação musical, assim como aplicativos no ensino da música. Para avaliar efetividade do aplicativo, Brasileiro (2017) contou com participantes que se disponibilizaram a testá-lo. Os resultados apontaram como ponto negativo, a falta de treinamento em leitura de partitura e o fato do aplicativo não fornecer idioma Português. Como ponto positive, o fato de fazer com que o usuário sinta a necessidade de evoluir e subir de nível dentro da aplicação por gamificação, gerando motivação para $o$ aprendizado do instrumento.

Ao se analisar tais aplicativos existentes no mercado atualmente e trabalhos relacionados publicados, se percebe que ainda há o que ser feito no ensino do violão, por aplicativos móveis. Apesar de existirem bons produtos similares disponíveis e outras formas de aprender música por computador, como o jogo Rocksmith e programas como o Garage Band, barreiras são encontradas por pessoas que buscam aprender, como o preço de serviços completos, o idioma e limitações de fucionalidades/recursos impostas nas versões gratuitas, sendo esses os principais diferenciais do aplicativo proposto, que propõe solução prática para problemas encontrados nos produtos atuais.

\section{Método de Pesquisa}

Essa pesquisa adota o método Design Science Research (DSR) na execução, projeto, desenvolvimento e avaliação do artefato (Dresch, Lacerda e Antunes, 2015), com ciclos 
de investigação (Pimentel, Filippo e Santoro, 2020): ciclo de conhecimento ou do rigor, ciclo de design ou de engenharia e o ciclo de relevância. Para sustentação teórica, conscientização do problema, entendimento de requisitos e modelagem do protótipo foram realizadas: revisão de literatura, pesquisa de produtos similares no mercado e entrevista com especialista em música. A classe de problemas e unidade de análise tratase do ensino de música, com ênfase no instrumento de violão, via aplicativo móvel.

A etapa de coleta de dados envolveu entrevista de um especialista, definido por conveniência, com atuação no ensino de música desde 2015, técnico na área, além de graduando em Música, com especialização em violão erudito. $\mathrm{O}$ roteiro tinha questões sobre requisitos e conteúdos cujas respostas serviram de base para engenharia dos requisitos e construção das aulas e material didático, a ser disponibilizado no aplicativo. Após projeto e desenvolvimento da versão inicial do protótipo, interessados foram convidados pelas redes sociais (Facebook, Instagram, LinkedIn e WhatsApp) e e-mail, para ajudar na divulgação e participar da avaliação, no período entre 17 de maio e 3 de junho de 2021, sendo apoiados por um guia rápido. Quanto aos níveis de proficiência, os 12 participantes variaram entre perfis iniciantes e especialistas. Após testes e uso, eles responderam ao questionário de avaliação no Google Forms, com questões baseadas no referencial teórico e na pesquisa de produtos similares. Das respostas dessa avaliação preliminar extraiu-se informações relevantes sobre percepção de relavância e utilidade da solução e para aprimoramentos no protótipo. Os dados qualitativos foram analisados por meio de análise de conteúdo, servindo de base para o material didático e requisitos da solução proposta. Já, os dados quantitativos obtidos do questionário foram analisados por estatística básica. Com esses dados, se avaliou quanto o aplicativo estava cumprindo o seu objetivo, num primeiro ciclo de avaliação executado, sob DSR.

Em resumo, a pesquisa seguiu essas etapas e atividades (Dresch, Lacerda e Antunes, 2015): (i) Conscientização: tratou de identificar e entender o problema a ser resolvido, assim como a performance necessária. Em tal etapa se estudou o referencial teórico e especificações do projeto na seção 4; (ii) Sugestão: sugestão de solução para o problema feita através da proposta de aplicativo voltado ao ensino do violão, com gamificação para melhor engajamento do usuário; (iii) Desenvolvimento: envolveu o projeto e o desenvolvimento do artefato proposto na etapa anterior, com versão inicial do protótipo; (iv) Avaliação: num primeiro ciclo, o protótipo desenvolvido foi avaliado na prática por interessados, em contexto real e com base na percepção da experiência ao usá-lo, via aplicação de questionário; (v) Conclusão: apresentação de resultados parciais obtidos com o uso e testes, avaliando-se lições aprendidas e ajustes necessários para a repetição do design cycle, sendo por isso que o Violearn ainda não foi disponibilizado.

\section{Resultados}

Nesta seção são apresentados os requisitos, a arquitetura, o projeto, o desenvolvimento e os resultados do ciclo preliminar de avaliação do protótipo da solução dessa pesquisa.

\subsection{Requisitos de Funcionamento da Solução}

Os requisitos funcionais iniciais foram levantados por entrevista, literatura e produtos similares. Em resumo, os principais acerca do conteúdo de aulas são: (i) Tempo de estudo recomendado deve ser de 15 a 60 minutos por dia; (ii) As videoaulas devem ser divididas em tempos entre 5 e 10 minutos; (iii) Aulas com o ensino de alguns acordes e uma levada; (iv) Disponibilizar aula de pelo menos 5 músicas populares, a fim de 
motivar o aluno; (v) Videoaulas devem apresentar tablatura do que foi ensinado. Já, os requisitos funcionais do aplicativo em si são: (i) Sistema de pontos por aulas e módulos concluídos; (ii) Aulas divididas por módulos que representam uma semana de estudo; (iii) Permitir alterações de nome e senha na conta; (iv) Permitir envio de foto de perfil; (v) Sistema de login e logout; (vi) Sistema de módulos de aulas; (vii) Área com ensino de músicas populares para o usuário escolher; (viii) Permitir ao usuário voltar a última aula assistida; (ix) Exibir para o usuário o tempo assistido de cada aula.

Conforme Sommerville (2011), os requisitos não funcionais organizacionais de desenvolvimento são: (i) Desenvolvimento em linguagem JavaScript e biblioteca React Native para construção da interface; (ii) Uso da ferramenta Expo para gerar build em Android e $i O S$, usando o mesmo código; (iii) Uso do aplicativo Expo para testagem do protótipo no smartphone; (iv) Desenvolvimento do Backend da aplicação com o framework NodeJS; (v) Repositório na plataforma GitHub, que usa o versionador de códigos git e controle de versão, facilitando manutenção; (vi) Edição do texto no Visual Studio Code, devido fácil integração com GitHub, o que facilita o desenvolvimento; (vii) Uso do sistema operacional Windows 10 Pro; (viii) Máquina com 16GB de memória RAM, 1TB de disco rígido, 512MB de SSD, processador AMD Ryzen 53600 de 6 núcleos e 16 threads e a placa de vídeo AMD RX5500 XT de 8GB. Ressalta-se que para o desenvolvimento do protótipo, ainda não foi usado NodeJS como framework para backend. Optou-se pelo JSON Server, para simular uma API Rest, na construção desse Mínimo Produto Viável (MVP). Essa decisão técnica se deu pela agilidade proporcionada pela ferramenta para fins de prototipação, visto que não é necessária a complexidade de um backend completo para esta etapa.

Dê início, em requisitos não funcionais operacionais têm-se apenas que o aplicativo deve suportar os sistemas operacionais Android e IOS. Como requisitos não funcionais de produto foram elicitados nas subcategorias: a) Usabilidade: (i) Aplicativo deve possuir interface amigável e intuitiva, com elementos principais, como módulos e aulas, bem destacados na tela e tempo de aprendizagem de uso máxima de 5 minutos; (ii) Guardar informações de aulas assistidas por aluno, assim como o tempo assistido da aula pelo aluno; (iii) $\mathrm{Na}$ navegabilidade, apenas permitir ao aluno ir para o módulo seguinte, quando concluir o módulo atual; b) Eficiência: (i) Tempo máximo para carregamento do aplicativo deve ser de 5 segundos; (ii) Disponibilizar as aulas no YouTube e incorporá-las para maior desempenho na reprodução e menor espaço de armazenamento; c) Proteção: (i) Utilizar sistema de sessão do usuário, permitindo login e logout; (ii) Requisitar senha de cadastro de pelo menos 8 dígitos; (iii) Senhas devem ser criptografadas antes de salvas no banco de dados.

\subsection{Arquitetura, Modelagem e Prototipagem da Solução}

A Figura 1 mostra a arquitetura da solução, denominada de Violearn. O aplicativo é instalado no smartphone, que o executa. $\mathrm{O}$ usuário dá comandos e o aplicativo requisita para a Application Programming Interface (API), que se comunica com o banco de dados para buscar, criar, atualizar ou excluir dados, conforme requisitado, via aplicativo. Realizado este processo, o banco de dados retorna resposta para a API, que por sua vez trata o retorno do banco de dados, conforme regra de negócio desenvolvida e envia estas informações para o aplicativo, que monta a tela exibindo-a para o usuário.

Destaca-se que o protótipo do Violearn é classificado como software de tutorial (Nart, 2016), por apresentar conteúdo audiovisual, informações teóricas, explicações e 
definições sobre música, violão e como tocá-lo, sem interatividade entre o usuário e a aplicação. Ademais foram modelados diagramas de Casos de Uso, de Classes e de Entidade-Relacionamento, com base nos requisitos, casos de uso especificados e nessa arquitetura projetada, mas suprimidos devido ao limite de páginas, na Figura 1.

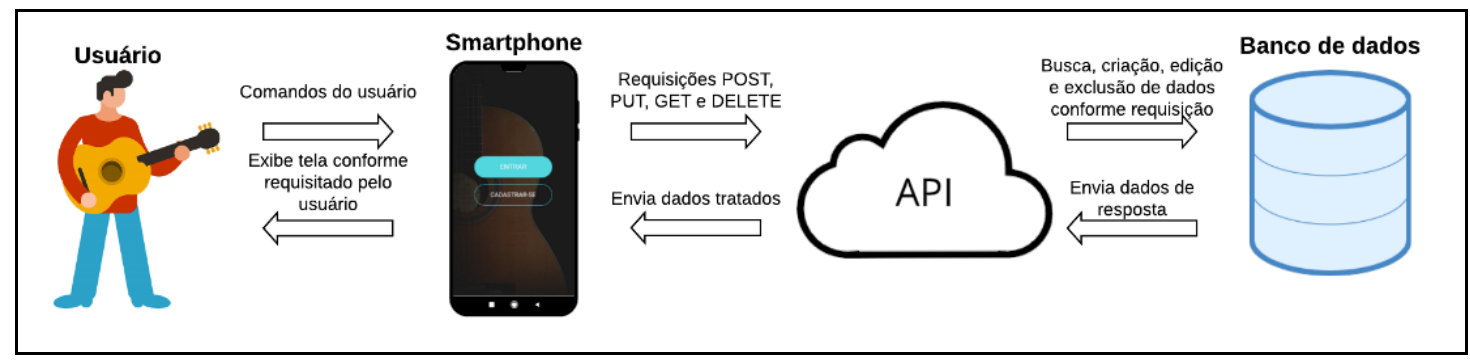

Figura 1 - Arquitetura da solução

No que tange à prototipação inicial foram criadas telas principais do aplicativo, por meio da Figma (2020), conforme Figura 2. Nessa figura, em (a) é possível ver a tela inicial, que solicita ao usuário entrar em sua conta ou cadastrar nova. Feito o cadastro, o aluno é levado à página principal, em que escolhe o módulo que deseja estudar. Vale destacar que o aluno não poderá acessar módulos seguintes, sem antes ter completado os anteriores, o que é demonstrado visualmente na segunda tela da Figura 2(b).

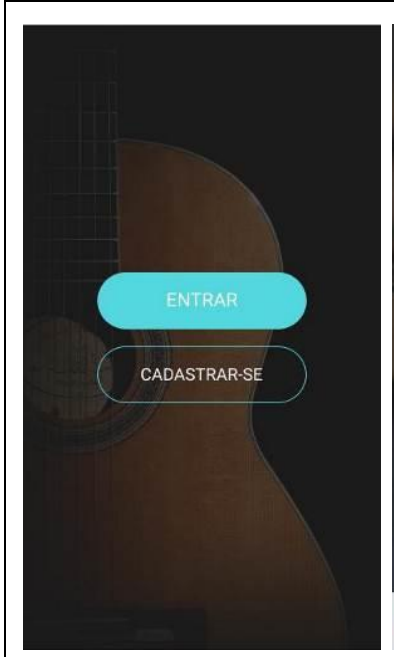

(a)

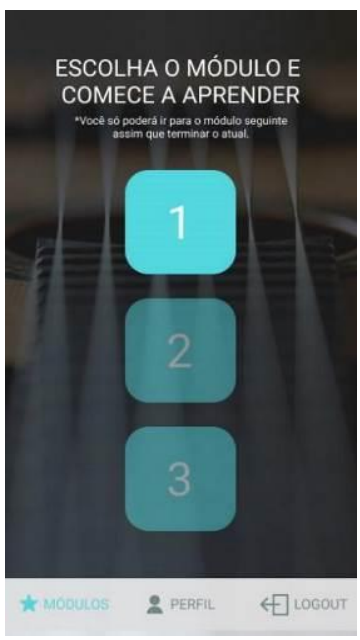

(b)

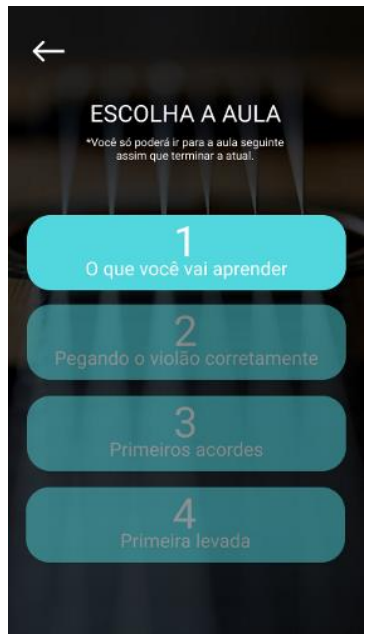

(c)

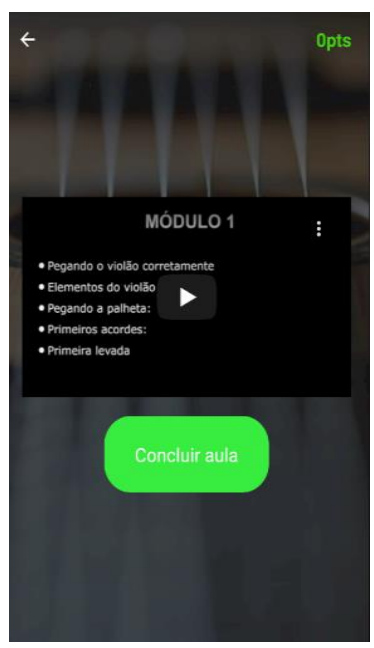

(d)

\section{Figura 2 - Telas principais do aplicativo}

A Figura 2(c) refere-se à escolha da aula dentro do módulo, onde não é possível escolher a aula seguinte, sem ter completado a anterior. Na Figura 2(d) é demonstrada a tela de uma aula específica, que possui a videoaula, o botão de conclusão e a pontuação atual do usuário, que é alterada cada vez que uma aula é completada. Ao concluir a aula, o aluno ganha quinhentos pontos, exibidos na parte superior direita, conforme Figura 2(d), em fonte na cor verde. Esta pontuação faz parte do sistema de gamificação, implementado para manter o aluno engajado e motivado nas aulas. Por enquanto, o protótipo inclui o Módulo 1, com sete aulas ao total. Nestas aulas se abordam como segurar corretamente o violão, os principais elementos do violão, como segurar a palheta, introdução aos três acordes e a primeira levada no violão. Nas aulas em que os 
acordes são mostrados é usado o sistema de notação, chamado de tablatura, para facilitar o entendimento do aluno. Esse conteúdo foi construído com o especialista.

Assim como ao longo da história da música tem-se aprimorado a maneira como se aprende e se ensina música, este protótipo busca criar uma forma diferente e moderna de transmitir conhecimento musical. O material didático do protótipo apoia-se no estudo histórico feito, desde a criação das primeiras escalas e notação musical, até o avanço tecnológico necessário e presente no protótipo, tendo cada período histórico da música e suas características de educação contribuído neste estudo. Destaca-se como exemplo prático dessa contribuição, o uso da tablatura, sistema usado pelos alaudistas na Renascença (Grout e Palisca, 1988), abordado na aula sobre os primeiros acordes.

\subsection{Avaliação da Solução por Usuários Potenciais}

Doze pessoas participaram do primeiro ciclo de da avaliação do protótipo, sendo 2 destes considerados especialistas. Quanto ao nível de conhecimento e de experiência musical dos usuários, a maioria se considerou ter experiência e conhecimentos baixos ou muito baixos. Pelo fato da avaliação ser voluntária, esses resultados permitem entender essa maioria como potenciais alunos, interessados na solução proposta.

Sobre o ambiente do usuário, como o modelo do celular e a versão do sistema operacional (SO), as respostas foram úteis para fins de mapeamento e depuração de problemas encontrados em ambiente real de uso, permitindo identificar modelos e versões de SO dos dispositivos móveis homologados. Dessa forma, a plataforma Expo, usada para testagem do protótipo, não funcionou para parte dos usuários de Iphone. Como solução paliativa foi gerada versão web do protótipo, para que tais usuários pudessem completar a avaliação. Ressalta-se que tal problema se refere apenas ao ambiente de testes, não existindo quando o aplicativo estiver pronto.

De forma unânime, quanto ao funcionamento notou-se que nenhum participante relatou ter tido dificuldades para entender o funcionamento do protótipo nem dificuldades de utilização do protótipo. Sobre a usabilidade, especialistas justificaram suas respostas relatando ser ter interface intuitiva, organizada e coerente. Do ponto de vista dos demais usuários houveram relatos de dificuldades em entender como sair de uma aula e o funcionamento do botão de conclusão da aula. Quanto à gamificação notou-se que o sistema de pontos implementado auxiliou na motivação dos estudos para ambos os perfis, com sugestões de melhoria para que a pontuação seja gradativa ou apenas ao fim do módulo, para dar sensação de maior desafio para o usuário. Outra foi adicionar possibilidade do uso dos pontos para além de acompanhamento do progresso.

Sobre funcionalidades, os usuários não sentiram falta de outras, mas, em relação às melhorias teve sugestões acerca da possibilidade de login integrado ao Facebook ou Google. Quanto ao material didático, os usuários responderam positivamente para a clareza na explicação do conteúdo nas aulas. Entre os motivos, o fato das aulas criadas serem simples, claras e rápidas, sendo características consideradas satisfatórias para os usuários iniciantes. Todos responderam não sentir falta de outros conteúdos nas aulas e consideraram o atual relevante no aprendizado. Entre explicações dos especialistas, o fato do conteúdo das aulas abranger os principais tópicos do primeiro nível de aprendizado do violão. Na visão dos demais usuários, o fato de terem conseguido aprender conteúdos novos, apesar do baixo conhecimento prévio. 


\subsection{Discussão}

Em geral, esse primeiro ciclo de avaliação obteve resultados positivos, corroborando com Santana e Rovaron (2020), na direção de que os aplicativos auxiliam no ensino e prática musical. Conforme dados obtidos nas dimensões de experiência do usuário e usabilidade, o protótipo demonstrou ser organizado, intuitivo e agradável em sua interface. Uma possível explicação pode ser o fato dela ter sido inspirada em produtos similares (Brasileiro, 2017), aumentando aceitação e diminuindo estranheza, por possível experiência prévia dos usuários, com interfaces semelhantes. A quantidade não exacerbada de elementos passíveis de interação na tela também pode ter facilitado a navegação, diminundo a chance de confusão. Entretanto, na tela que contempla a aula em si, usuários relataram que a troca de aula não foi intuitiva, sendo necessário voltar ao menu de aulas. Pode-se implementar funcionalidade de levar o usuário direto para a próxima aula, assim que a atual for concluída. Um tutorial introdutório acerca da interface de usuário pode ajudar a mitigar este problema também.

Quanto ao sistema de gamificação, todos relataram motivação em razão dos pontos no protótipo, convergindo com Brasileiro (2017). Usuários se sentiram motivados a subir de nível, aumentando o engajamento nas aulas e motivando a adquirir nova habilidade musical (Burke, 2014). Sugestões foram dadas, como troca de pontos por algo e uma pontuação gradual, conforme o usuário avança as aulas nos módulos, ao invés de uma pontuação estática e igual para todas as aulas. Assim, a gamificação carece de refinamentos, visto que recompensas não estão sendo tão efetivas quanto deveriam para manter o aluno motivado (Fardo, 2013). Pode-se adicionar níveis, em que à medida que se conclui certo número de aulas, ganha-se pontos e aumenta de nível, bem como aumenta o esforço necessário para alcançar o próximo nível.

Quanto à adequação funcional, todos relataram não sentir falta de outras funcionalidades, mas houveram sugestões de melhoria na navegabilidade do protótipo. No quesito material didático, os usuários ficaram satisfeitos com o que foi apresentado, comentando sobre a clareza na transmissão do conteúdo, simplicidade, objetividade e de fácil entendimento. Um deles citou que gostaria de ver conteúdos mais avançados, embora, esse não fosse o objetivo da versão inicial do protótipo. Sobre relevância para aprendizado, todos responderam positivamente. Os especialistas comentaram que foram cobertos todos os pontos necessários para iniciantes, abrangendo principais tópicos. Em geral, os resultados satisfatórios se explicam pelo amplo e profunda elicitação de requisitos, para criação do material e do protótipo, conforme técnicas de engenharia de requisitos (Sommerville, 2011) e rigor téorico-prático de DSR (Dresch, Lacerda e Antunes, 2015). Apesar de ser protótipo, os objetivos foram alcançados, fornecendo conteúdo útil e relevante para ensino da música por violão, de forma simples e gratuita.

\section{Considerações Finais}

No decorrer dessa pesquisa compreendeu-se melhor a história da música e seu ensino. A revisão de literatura proporcionou clareza e base necessária para buscar o rumo a ser tomado. A análise de produtos similares forneceu auxílio na identificação de pontos positivos e negativos, ajudando na conscientização acerca do problema, assim como no levantamento de requisitos e a elaboração de telas principais do protótipo do aplicativo sugerido, conforme DSR. 
Com o material didático da versão inicial do protótipo e o levantamento dos requisitos da solução foram alcançados os objetivos específicos (i) e (ii). Depois, esses objetivos possibilitaram o projeto e desenvolvimento do protótipo inicial do aplicativo, submetido num primeiro ciclo de avaliação à apreciação e testes de usuários interessados (voluntários e especialistas), aferindo utilidade e desempenho deste na resolução do problema identificado, alcançando-se os objetivos específicos (iii) e (iv). Percebe-se com esta pesquisa, que os dispositivos móveis são bons aliados ao ensino, o que corrobora com os resultados dos trabalhos relacionados. No que tange ao ensino da música por violão, a união de uma trilha de estudos, através de módulos, com o sistema de gamificação para engajamento do aluno se mostrou útil, para quem deseja aprender música e a tocar o instrumento.

A partir dos resultados obtidos nesse primeiro protótipo, o aplicativo a ser desenvolvido futuramente poderá auxiliar pessoas, que buscam aprender música e violão, mas não tem as condições necessárias para ter aulas particulares com um professor ou pagar mensalidade de outros cursos disponibilizados na Internet. $\mathrm{O}$ aplicativo poderá ser usado como um suporte ou até mesmo, como guia para professores de música, podendo usufruir do conteúdo disponível nele em suas aulas, gratuitamente. Apesar dos problemas encontrados por usuários de Iphone, o Expo (2021) e o React Native (2021) demonstraram ser úteis e versáteis, para desenvolvimento de aplicações, que não dependem de altíssima performance. A adoção destas ferramentas possibilitou solucionar o problema da testagem do protótipo em dispositivos Iphone rapidamente, pois possuem possibilidade de geração de versão web. Essa estratégia simplificou e agilizou na prototipação, pois pode-se testar o protótipo no celular em todo processo do desenvolvimento, sem geração de build e a transferência para smartphone, a todo momento. Da mesma base de código é possível gerar versão para Iphone e Android.

Quanto à informática na educação, essa pesquisa contribuiu ao apresentar protótipo de uma solução tecnológica para o ensino da música por violão. Os resultados corroboram com pesquisas anteriores, ao demonstrar que o uso de dispositivos móveis pode ser útil na aprendizagem de conhecimento musical. Pode-se validar na prática, o valor agregado que os dispositivos móveis e jogos digitais podem fazer pela educação como um todo, não apenas à música e ao violão. Outra contribuição importante é o uso de determinadas ferramentas no processo de desenvolvimento, com compartilhamento de lições aprendidas. Ademais, a pesquisa fornece caso prático de seu uso, auxiliando no desenvolvimento de futuras soluções semelhantes.

Como trabalhos futuros deseja-se aprimorar a interface do usuário, conforme sugestões obtidas no primeiro ciclo de avaliação. Assim como, o aprimoramento e a adição de conteúdos programáticos avançados e um módulo introdutório sobre a história da música. Ainda, em relação ao material didático, disponibilizar tutoriais ensinando a tocar, ao menos, 5 músicas populares, requisito não contemplado neste MVP. Quanto à gamificação, aprimorar o sistema de pontuação, com diferentes níveis e premiações, para sensação de maior dificuldade e conquista, quando alcançado um nível mais alto. Considera-se adicionar requisito funcional referente ao afinador de violão, para que o aluno consiga afinar seu violão, sem usar aplicativo separado para isso. Além de ciclos de avaliação de nova versão do protótipo, validação de viabilidade e utilidade de versão web do aplicativo, com funcionalidades adequadas para usuários de computadores e notebooks. Por fim, validação do protótipo por tempo maior de uso, em aulas de professores de música, para verificar se existem ganhos no aprendizado. 


\section{Referências}

ABRAMUS (2019) "Pesquisa Comportamento do Consumidor: Música", Opinion Box, https://d335luupugsy2.cloudfront.net/cms/files/7540/1556130050OPB_pesquisa_co mportamento_musica_infografico_final_links.pdf

Brasileiro, F. A. (2017) “A Utilização de Aplicativos para Smartphones no Aprendizado de Instrumentos Musicais: Uma Análise Sobre o Yousician”, https://repositorio.ufu.br/handle/123456789/20289

Burke, B. (2014) "Gamify: How Gamification Motivates People to do Extraordinary Things", Bibliomotion, Inc.

Ceccon, D. L.; Porto, J. B. (2020) "BcS: Jogos Digitais no Auxílio do Desenvolvimento de Crianças Especiais com Atraso na Linguagem", In Anais do XXXI SBIE, Online, p. 522-531, https://doi.org/10.5753/cbie.sbie.2020.522

Cogo-Moreira, H. et al. (2013) "Effectiveness of Music Education for the Improvement of Reading Skills and Academic Achievement in Young Poor Readers: A Pragmatic Cluster-Randomized, Controlled Clinical Trial”, Plos One, https://doi.org/10.1371/journal.pone.0059984

Expo (2021) “Expo - Versão 40.0.0”, https://expo.io/

Figma (2020) "Welcome to FigJam", https://www.figma.com/

Fonseca, A. (2013) "Aprendizagem, Mobilidade e Convergência: Mobile Learning com Celulares e Smartphones", Revista Eletrônica do Programa de Pós-Graduação em Mídia e Cotidiano, https://periodicos.uff.br/midiaecotidiano/article/view/9685

Grout, D. J.; Palisca, C. V. (1988) "A History of Western Music", W. W. Norton \& Company, Inc.

IBGE (2020) "PNAD Contínua TIC 2018: Internet chega a 79,1\% dos domicílios do país", Agência IBGE Notícias, https://agenciadenoticias.ibge.gov.br/agencia-sala-deimprensa/2013-agencia-de-noticias/releases/27515-pnad-continua-tic-2018-internetchega-a-79-1-dos-domicilios-do-pais

Nart, S. (2016) "Music Software in the Technology Integrated Music Education", The Turkish Online Journal of Educational Technology, https://files.eric.ed.gov/fulltext/EJ1096456.pdf

Pimentel, M.; Filippo, D.; Santoro, F. M. (2020) "Design Science Research: fazendo pesquisas científicas rigorosas atreladas ao desenvolvimento de artefatos computacionais projetados para a educação", In: Jaques, P. A.; Pimentel, M.; Siqueira; S.; Bittencourt, I. (Org.) Met. de Pesquisa Científica em Informática na Educação: Concepção de Pesquisa (Série Metodologia de Pesquisa em Informática na Educação, v. 1), SBC, Porto Alegre, https://metodologia.ceie-br.org/livro-1/

React Native (2021) "React Native", https://reactnative.dev/

Santana, J. C. S.; Rovaron, R. (2020) "Desenvolvimento de um aplicativo para dispositivo móvel para estudo da teoria musical e abordagem prática para tocar violão", Intellectus Revista Acadêmica Digital, http://www.revistaintellectus.com.br/artigos/71.883.pdf 
Scotti, A. (2011) "Violão.org: saberes e processos de apreensão/transmissão da música no espaço virtual", https://repositorio.ufu.br/handle/123456789/12279

Sommerville, I. (2011) “Engenharia de Software”, Pearson, São Paulo.

UNA-SUS (2020) "Organização Mundial de Saúde declara pandemia do novo Coronavírus", https://www.unasus.gov.br/noticia/organizacao-mundial-de-saudedeclara-pandemia-de-coronavirus

Wee, J. L. K. (2010) “GuitarApprentice: A Mobile Application for Acoustic Guitar Learning using Fast Fourier Transform algorithm”, http://utpedia.utp.edu.my/id/eprint/13552 